\title{
IDENTIFICACIÓN DEL AGENTE CAUSAL DEL MARCHITAMIENTO EN Caesalpinia spinosa "tara" Y EL EFECTO ANTAGÓNICO DE AISLADOS DE Bacillus spp. y Trichoderma sp.
}

\section{IDENTIFICATION OF THE CAUSAL AGENT OF THE WILTING OF Caesalpinia spinosa "tara" AND THE ANTAGONIC EFFECT OF Bacillus spp. and Trichoderma sp. ISOLATES}

\author{
Dayvi Pérez ${ }^{1}$ y Paula García-Godos ${ }^{2}$
}

\begin{abstract}
Resumen
La enfermedad denominada marchitamiento vascular es un problema que produce perdidas en la producción de los cultivos de Caesalpinia spinosa "tara". El objetivo de la investigación fue identificar el agente causal del marchitamiento y determinar el efecto antagónico de cepas de Bacillus spp. y Trichoderma sp. Fueron muestreadas plantas de tara con síntomas de la enfermedad y desde el suelo. Se aislaron 27 cepas de hongos filamentosos que fueron identificados mediante el método de Pitt basado en las claves taxonómicas. El efecto antagónico se realizó mediante pareamientos in vitro en medio Agar Papa Dextrosa, enfrentando a cepas de Fusarium spp. con dos cepas de Trichoderma sp. y 18 de Bacillus spp. como potenciales antagonistas. Los resultados constataron que las cepas de Fusarium spp., son las causantes del marchitamiento vascular progresivo en tara. La evaluación del antagonismo in vitro mediante contacto directo, indicó que las cepas de Bacillus spp. TBa 4, TBa 6, TBa 9, TBa 11 y TBa 18 tuvieron un mayor efecto alcanzando entre $88.9 \%$ y $93.3 \%$ de inhibición de Fusarium. Las pruebas de antagonismo en cultivos duales, mostraron que las cepas TBa 4, TBa 6 , TBa 11 y TBa 18 alcanzaron los mayores niveles de inhibición del patógeno, fluctuando entre $92.2 \%$ y $90.0 \%$; entretanto, las cepas de Trichoderma sp. y $T$. viridae, obtuvieron $77.8 \%$ y $74.4 \%$ de inhibición del patógeno, respectivamente. El grado de inhibición in vitro alcanzado por las cepas de Bacillus spp., permite considerarlas como potenciales agentes de control biológico contra Fusarium spp. en cultivos de tara.

Palabras clave: marchitamiento vascular, efecto antagónico, Bacillus spp., Trichoderma sp., Fusarium spp.
\end{abstract}

\begin{abstract}
The disease called vascular wilt is a problem that causes production losses in the Caesalpinia spinosa "tara" crops. The objective of the research was to identify the causal wilting agent $\mathrm{t}$ and to determine the antagonistic effect of Bacillus spp. and Trichoderma sp. strains. Tara plants with symptoms of the disease and from the soil were sampled. We isolated 27 strains of filamentous fungi that were identified by the Pitt method based on taxonomic keys. The antagonistic effect was achieved through in vitro pairing in Papa Dextrose Agar medium, facing strains of Fusarium spp. with two strains of Trichoderma sp. and 18 of Bacillus spp. as potential antagonists. The results showed that the strains of Fusarium spp. are the cause of the progressive vascular wilting in tara The evaluation of in vitro antagonism by direct contact, indicated that strains of Bacillus spp. TBa 4, TBa 6, TBa 9, TBa 11 and TBa 18 had a greater effect reaching between $88.9 \%$ and $93.3 \%$ inhibition of Fusarium. In the tests of antagonism in dual cultures, they showed that the strains TBa 4, TBa 6, TBa 11 and TBa 18 reached the highest levels of inhibition of the pathogen, fluctuating between $92.2 \%$ and $90.0 \%$; meanwhile, strains of Trichoderma sp. and T. viridae they obtained $77.8 \%$ and $74.4 \%$ inhibition of the pathogen, respectively. The degree of in vitro inhibition achieved by Bacillus spp. strains makes it possible to consider them as potential biological control agents against Fusarium spp. in tara cultures.
\end{abstract}

Key words: vascular wilt, antagonistic effect, Bacillus spp., Trichoderma sp, Fusarium spp.

\section{Introducción}

Caesalpinia spinosa (Molina) Kuntze ("tara") es una especie forestal que viene adquiriendo una demanda creciente por sus múltiples usos, ya sea medicinal, alimenticio e industrial; productora de taninos y de la que se obtienen tintes con fines 
comerciales (De La Cruz, 2004). El avance en las investigaciones sobre el comportamiento de la dinámica biológica de plagas y su interacción con el ambiente han sido determinantes para el desarrollo de métodos de control que enfatizan al manejo sostenible del predio agrícola a través del manejo integrado de las plagas. Las plagas presentes en $C$. spinosa aún no son importantes, pero con el incremento progresivo de las áreas de cultivo de esta especie se determinará un entorno favorable para que la plaga sea más nociva, por tanto, es relevante conocer las características de estas plagas para prevenir y contrarrestar los daños al cultivo, siendo fundamental una diagnosis correcta de las enfermedades (Ogata \& Zúñiga, 2008).

Una de las enfermedades que está diseminándose es el marchitamiento vascular progresivo en las plantas de tara, siendo la principal enfermedad en vivero y con menor incidencia en plantaciones. En vivero, la incidencia y severidad puede ser alta, dependiendo del origen y calidad de sustrato utilizado y la humedad del suelo. En plantación, las plantas infectadas pueden llegar a marchitarse completamente a los dos años. El agente causal del marchitamiento de la tara, desde las raíces afectadas, podrían ser los hongos de los géneros de Fusarium y Verticillium (Coca, 2009).

El objetivo de la investigación fue identificar el patógeno asociado al marchitamiento progresivo ("seca seca") de las planta de tara (C. spinosa) y evaluar el efecto antagónico de aislados de Bacillus spp. y Trichoderma sp. contra el hongo patógeno causante de la enfermedad.

\section{Materiales y métodos}

$\underline{\text { Muestras de plantas }}$

Las muestras de plantas fueron obtenidas en el Distrito de Huamanguilla, Provincia de Huanta, Región de Ayacucho. Fueron recolectadas partes aéreas y radiculares de 15 plantas de tara con síntomas de marchitamiento desde diferentes campos de cultivo. Las muestras consistentes en hojas y tallos de hasta 10 $\mathrm{cm}$ se recolectaron con la ayuda de una tijera desinfestada, y las raíces se recolectaron con la ayuda de un pico esterilizado desenterrando las plantas completamente y evitando dañar la raíz. Además, fueron colectados plantines con síntomas de marchitamiento del vivero con baja intensidad de luz solar y se tomaron en su totalidad. Las muestras colectadas se colocaron en bolsas de polietileno individuales, herméticamente selladas y rotuladas.

Muestras de suelo

Las muestras se recolectaron de las partes circundantes de la zona radicular de las plantas de tara con síntomas, se tomaron aproximadamente $50 \mathrm{~g}$ de suelo, los que se rotularon y se transportaron en bolsas de polietileno color negro.

\section{Aislamiento de fitopatógenos}

\section{Aislamientos desde planta}

Fueron realizados a partir raíces, tallos y hojas. Las muestras de seis meses de edad fueron desinfestadas superficialmente con hipoclorito de sodio (5\%) y alcohol en una placa de Petri por $20 \mathrm{~min}$, luego se enjuagaron tres veces con agua destilada estéril, para luego ser sembradas en placas de Petri con Agar Papa Dextrosa (APD) en oscuridad, seguido de incubación por 5 días a $25^{\circ} \mathrm{C}$.

\section{Aislamientos desde suelo}

Se agregó $10 \mathrm{~g}$ de suelo en $90 \mathrm{ml}$ de agua peptonada al $0.1 \%$, luego homogenizamos y se realizaron diluciones sucesivas hasta $10^{-3}$ para sembrar por $1 \mathrm{ml}$ de la última dilución en placas de Petri con Agar Papa Dextrosa (APD), e incubándose a $25{ }^{\circ} \mathrm{C}$ por 5 días. Luego del tiempo de incubación, se seleccionaron las colonias con características macroscópicas distintas y se repicaron en tubos conteniendo medio APD y se almacenaron a $4{ }^{\circ} \mathrm{C}$, lo que conformaron el cepario fúngico (French \& Herbert, 1980).

Identificación de fitopatógenos

\section{a. Método de Pitt}

Del cepario fúngico se sembró por puntura en tres puntos equidistantes para cada placa de Petri conteniendo los medios Malta-Glucosa, CzapekLevadura y Czapek-Glicerol, para luego ser incubadas a $25{ }^{\circ} \mathrm{C}$ durante 7 días. Además, se sembraron dos placas de Petri con medio Czapek, que se incubaron a $5^{\circ} \mathrm{C}$ y $37^{\circ} \mathrm{C}$, durante 7 días (Fox, 1993; Pitt \& Hocking, 1997).

\section{b. Técnica de Microcultivo}

Se realizó usando las claves taxonómicas internacionales descritas por Carrillo (2003) de acuerdo con los criterios de morfología y color de colonia, picnidios, arreglo de las células conidiogénicas, tipo de conidiogénesis y el largo y ancho de conidios.

Pruebas de patogenicidad

Los ensayos de patogenicidad se basaron en lo descrito por Valencia-Botín (2002). Se utilizaron las cepas de Fusarium spp. M1R1 y M1R2, aisladas de plantas de tara en el presente estudio. Para ambas cepas fueron preparadas suspensiones de esporas, obtenidas a partir de las colonias de estos hongos crecidas en tubos de ensayo, en medio APD, incubadas por 10 días a 25 ${ }^{\circ} \mathrm{C}$. La colecta de esporas se realizó con agua peptonada al $0.1 \%$. El inóculo se preparó a partir de $5 \mathrm{ml}$ de la suspensión de esporas, que fueron colocadas en un matraz con $150 \mathrm{ml}$ con Caldo Papa Dextrosa (CPD), seguido de incubación a $25{ }^{\circ} \mathrm{C}$, agitado a $100 \mathrm{rpm}$ y aireación constante por 5 días. La suspensión final se ajustó a una concentración de $10^{4}$ esporas $/ \mathrm{ml}$.

Fueron inoculadas plantas de tara de dos meses, conservadas en el vivero del INIA - Ayacucho. Las plantas se trasplantaron a macetas de plástico con suelo esterilizado en autoclave y se mantuvieron en cuarentena por cuatro semanas en un vivero cerrado, garantizando condiciones de humedad del $80 \%$, 
temperatura de 16 a $20{ }^{\circ} \mathrm{C}$ y con riego cada 72 horas. Para el tratamiento se utilizaron diez plantas por cepa de Fusarium, las que fueron asperjadas con $50 \mathrm{ml}$ una suspensión de esporas por cepa de Fusarium, ocasionando previamente lesión en la epidermis, corteza, endodermis y parte de la médula de la raíz y el tallo por un tiempo aproximado de 5 minutos, junto con aplicar el inóculo de Fusarium directamente al suelo circundante a los pelos radicales de la planta (Monzón, 2000). A las plantas control se asperjó agua sin inoculo del patógeno. Las plantas después de la inoculación se mantuvieron en condiciones de humedad del $80 \%$, temperatura de 16 a $20{ }^{\circ} \mathrm{C}$ y con riego cada 72 horas. Las evaluaciones de las plantas se realizaron cada 24 horas por 30 días y las plantas que mostraron los signos y síntomas del marchitamiento progresivo se llevaron al laboratorio para el re-aislamiento del patógeno inicialmente inoculado (French \& Herbert, 1980).

Aislamiento de Bacillus spp. de muestras de suelo

Las cepas de Bacillus spp. se obtuvieron de $50 \mathrm{~g}$ de suelo rizósferico de las plantas de tara. Del suelo inicial se realizaron diluciones sucesivas hasta $10^{-3}$ en agua peptonada al $0.1 \%$, se tomó $1 \mathrm{ml}$ de la última dilución y se sembró en placas de Petri con medio de cultivo Agar Nutritivo. Las placas se mantuvieron a $37{ }^{\circ} \mathrm{C}$ por 24 horas hasta observar el desarrollo de las colonias con la morfología característica del género (forma estrellada o circular, borde entero, elevación convexa, superficie rugosa y color blanquecino). Luego, se realizó la caracterización microscópica de las colonias mediante tinción Gram, las que debían corresponder a bacilos en cadena y con esporas, procediéndose a realizar el cepario.

Evaluación del efecto antagónico de cepas de Bacillus spp.

\section{Por contacto directo}

Las cepas de Fusarium spp. (M1R1 y M1R2) se cultivaron por puntura en el centro de una placa de Petri con medio APD y se incubó por 10 días a $25{ }^{\circ} \mathrm{C}$ hasta cubrir toda la placa con el micelio del hongo, estas placas sirvieron para obtener discos de micelio del patógeno con un sacabocado. Se prepararon cultivos en suspensión de cada cepa de Bacillus en caldo nutritivo, los que se incubaron durante $48 \mathrm{~h}$, se colorearon las bacterias con azul de lactofenol, para luego ajustar la concentración a $10^{8}$ bacterias $/ \mathrm{ml}$ aproximadamente, mediante cámara de Neubauer, Se sembró por agotamiento con un hisopo $0.25 \mathrm{ml}$ de la suspensión bacteriana en una placa con medio APD. Con un sacabocado de $0.5 \mathrm{~cm}$ de diámetro se retiró el micelio de las cepas de Fusarium y se colocó el disco del micelio en la superficie del medio de cultivo en contacto directo con el centro de la placa de Petri sembrada previamente con Bacillus spp. Se incubaron a $25^{\circ} \mathrm{C}$ por 10 días evaluando cada $24 \mathrm{~h}$ el crecimiento del diámetro del hongo. Para cada cepa antagónica se realizó la prueba por triplicado (Mitidieri, 1988).

\section{Por cultivos duales}

Se colocó en un extremo de la placa de Petri un disco de micelio de $0.5 \mathrm{~cm}$ de diámetro del hongo patógeno tomado con un sacabocado. En la misma placa a $2.5 \mathrm{~cm}$ de separación se sembró frente a frente el antagonista bacteriano mediante estrías. Las placas se incubaron a $25^{\circ} \mathrm{C}$ durante 10 días y se evaluó cada $24 \mathrm{~h}$ el crecimiento del diámetro del hongo (Acosta et al., 2007).

Para el control de ambas pruebas, se hizo crecer en una placa con medio APD el hongo patógeno en las mismas condiciones pero sin el antagonista, durante 10 días hasta que la colonia del patógeno alcanzó el borde opuesto de la placa. Los ensayos se realizaron por triplicado y se evaluaron la tasa de crecimiento micelial (cm/día) y el porcentaje de inhibición. La tasa de crecimiento micelial (TC) se determinó considerando el diámetro de crecimiento de la colonia fúngica calculando su magnitud mediante la expresión sugerida (Benítez et al., 2004):

Donde:

$$
\mathrm{TC}=(\mathrm{Cf}-\mathrm{Ci}) /(\mathrm{Tf}-\mathrm{Ti}),
$$

Cf y $\mathrm{Ci}$ corresponden al diámetro final e inicial del patógeno, respectivamente, $\mathrm{y}$

Tf y Ti, al diámetro final e inicial en el testigo, respectivamente.

El porcentaje de inhibición del crecimiento micelial (ICM en \%) se calculó empleando la fórmula de Acosta et al. (2007):

Donde:

$$
\mathrm{ICM}=((\mathrm{R} 1-\mathrm{R} 2) / \mathrm{R} 1) * 100,
$$

R1 correspondió al crecimiento radial del testigo y R2 al crecimiento radial del patógeno en cada tratamiento.

Los datos obtenidos en las pruebas de antagonismo se evaluaron mediante el Análisis de Varianza, y las comparaciones múltiples con la prueba de Tukey con un nivel de significancia de $0.05 \%$.

\section{Resultados y discusión}

Se aislaron cepas de Fusarium spp. de diez árboles de tara con marchitamiento, y en medio de cultivo todas presentaron el mismo tipo morfológico de la colonia. Fueron seleccionadas dos cepas de Fusarium spp. (M1R1 y M1R2) para las prueba de patogenicidad en plantas de tara (Figura 1), las que causaron los síntomas específicos del marchitamiento vascular progresivo, según lo descrito por Valencia-Botín (2002), confirmando que especies de Fusarium como el agente causal de la enfermedad en el cultivo de tara en el Distrito de Huamanguilla. Según Coca (2009), un causante de marchitamiento vascular también podría corresponder a Verticillium spp., sin embargo, las pruebas de patogenicidad no mostraron sintomatología similar con este género fungoso. En el Perú es frecuente 


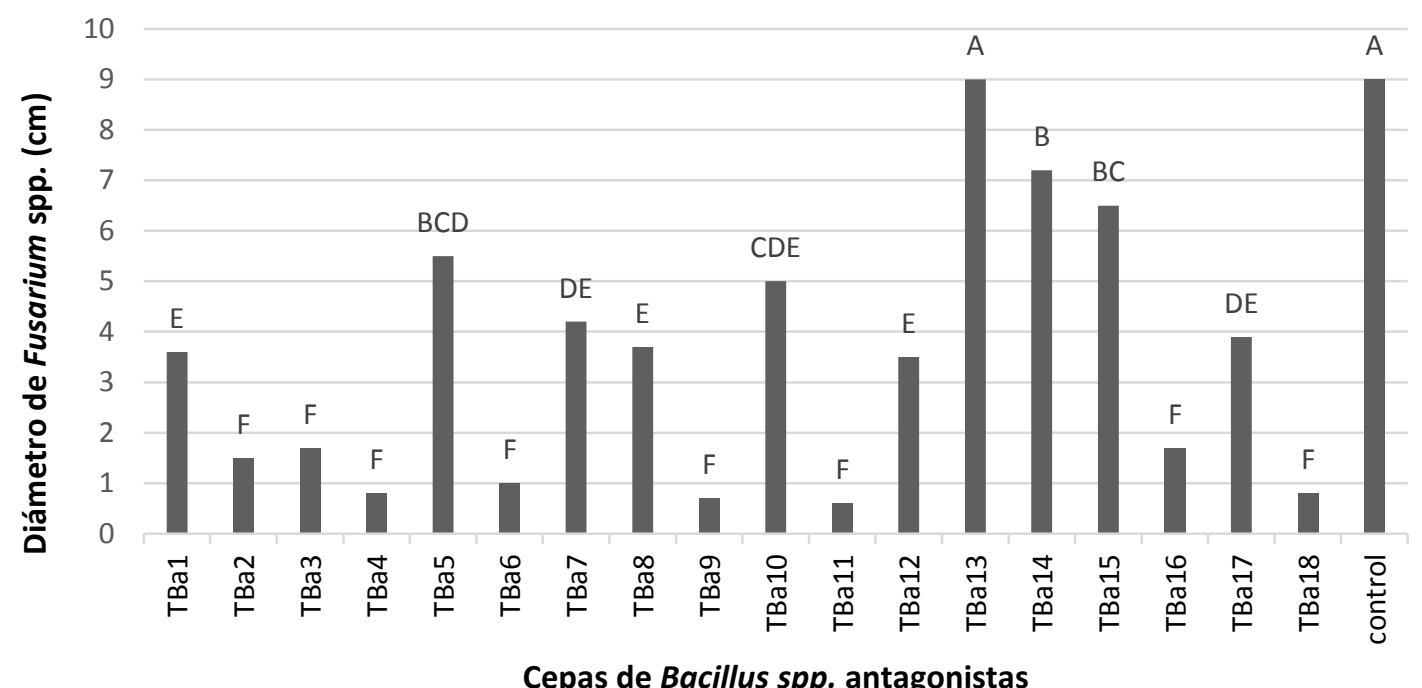

Figura 1. Efecto de cepas de Bacillus spp. (antagonistas) en el diámetro de colonia de Fusarium spp. en ensayo de antagonismo por contacto directo, después de diez días de incubación.

la infección del maíz por Fusarium spp., patógeno que se diseminada a partir de la semilla, lo que podría explicar la infestación de las plantas de tara por Fusarium spp. (Injante \& Joyo, 2010), considerándose que en el distrito de Huamanguilla las plantaciones de tara se realizan en cultivos mixtos con plantas de maíz.

Las cepas más eficaces de Bacillus spp. en la prueba de antagonismo por contacto directo frente a Fusarium spp. (Figura 1), correspondieron a las cepas TBa 4, 11, $9,18,6,2,16$ y 3 , evidenciando variaciones en el efecto inhibitorio de cepas de Bacillus spp. sobre el crecimiento micelial del patógeno. Las variaciones en el potencial biocontrolador in vitro de Bacillus spp. están asociadas generalmente a las características genéticas de la especie (Astorga et al., 2013; Calvo \& Zuñiga, 2010), reportándose una mayor actividad antagónica, en diferentes condiciones, a las especies $B$. brevis y B. subtilis (Layton et al., 2011). Estos datos son similares a los reportados por Corrales et al., (2012), donde obtuvieron tasas mínimas de crecimiento de hasta $0.08 \mathrm{~cm} /$ día de Fusarium frente a Bacillus en plantas de Tomillo (Thymus vulgaris). Constanza et al. (2011) en pruebas antagónicas de Fusarium frente a

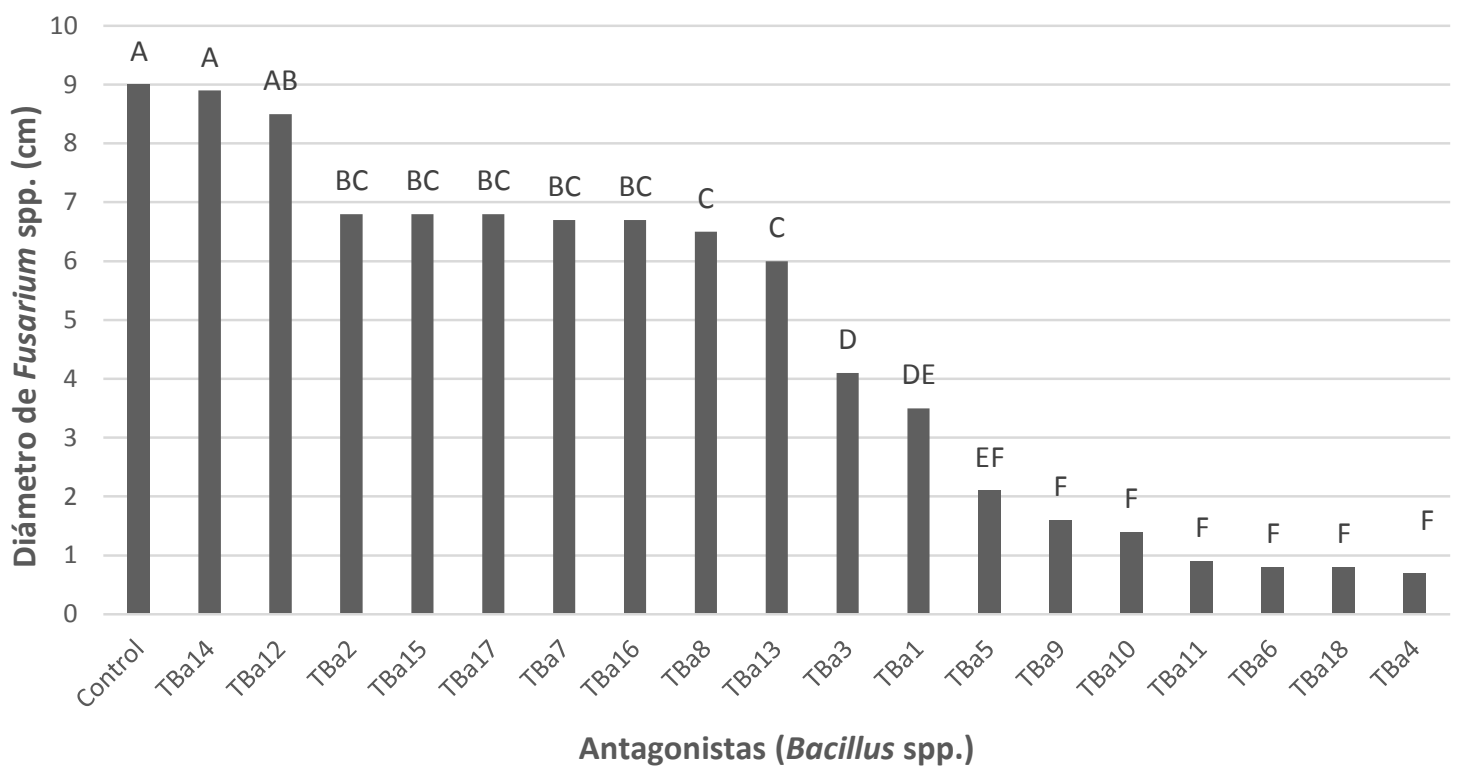

Figura 2. Efecto de cepas de Bacillus spp. (antagonistas) en el diámetro de colonia de Fusarium sp. en ensayo de antagonismo por cultivos duales, después de diez días de incubación. 


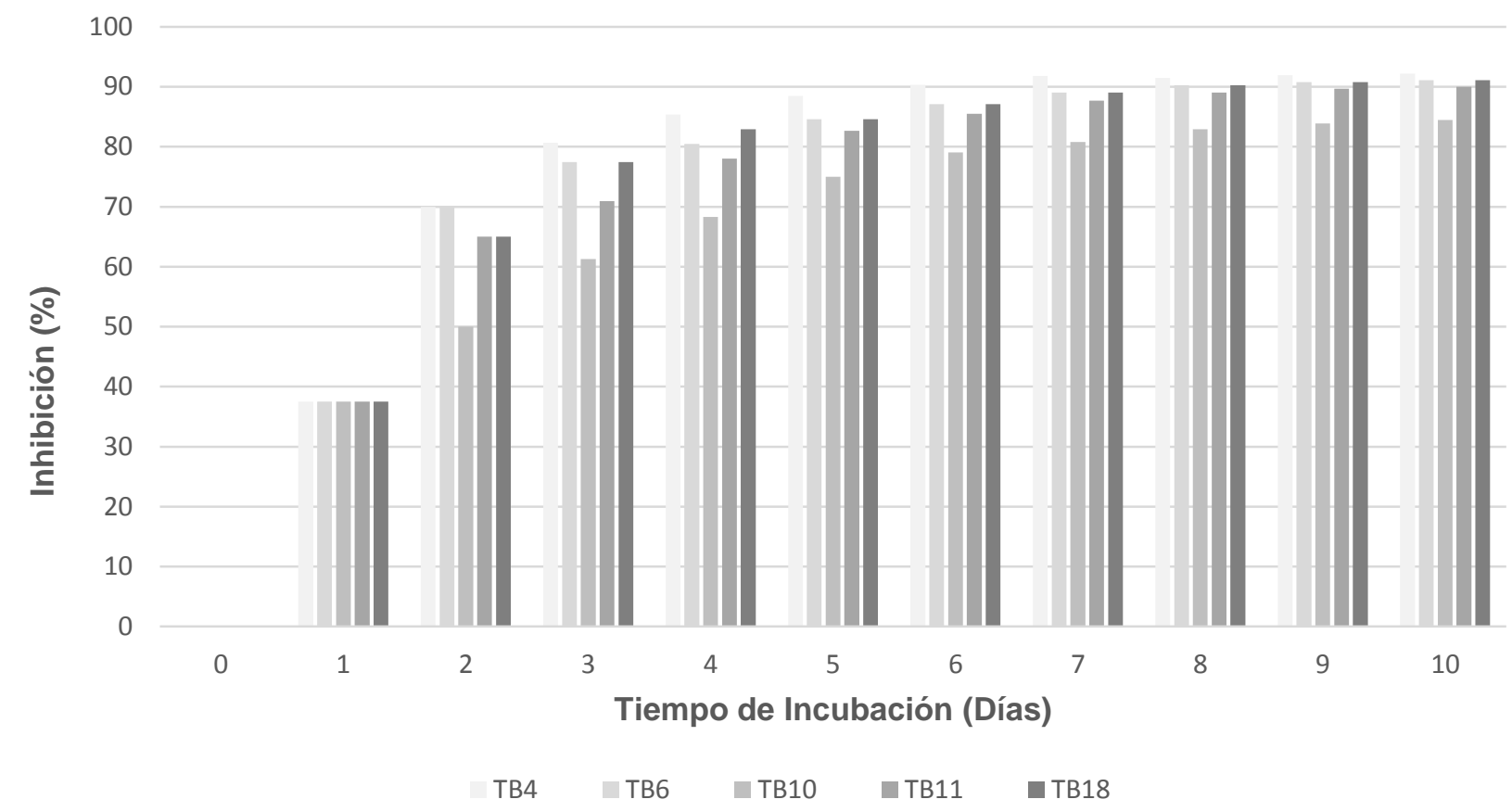

Figura 3. Porcentaje de inhibición del crecimiento micelial de Fusarium spp. frente a las cepas más eficaces de Bacillus spp. en prueba antagónica por cultivos duales.

Bacillus en Rosmarinus officinalis registraron tasas mínimas de crecimiento de hasta $0.17 \mathrm{~cm} /$ día.

El porcentaje de inhibición del crecimiento micelial de las cepas TBa 4, TBa 6, TBa 9, TBa 11 y TBa 18 reportando valores de $91.1 \% ; 88.9 \%$; $92.2 \% ; 93.3 \%$ y $91.1 \%$ respectivamente, demostrando una alta eficacia en la inhibición de Fusarium spp. en condiciones in vitro. Estos datos son similares a los reportados por Constanza et al., (2011), que señala entre 70 a $100 \%$ de inhibición en sus cepas más eficaces. Para poder demostrar la efectividad de la capacidad antagónica de Bacillus spp. se realizó una segunda prueba antagónica utilizando un método distinto, la de enfrentamiento por cultivos duales.

Referente al efecto inhibitorio que ejerció Bacillus spp. sobre el crecimiento del patógeno; las cepas de Bacillus TBa 4, 18, 6, 11, 10, 9 y 5 resultaron con

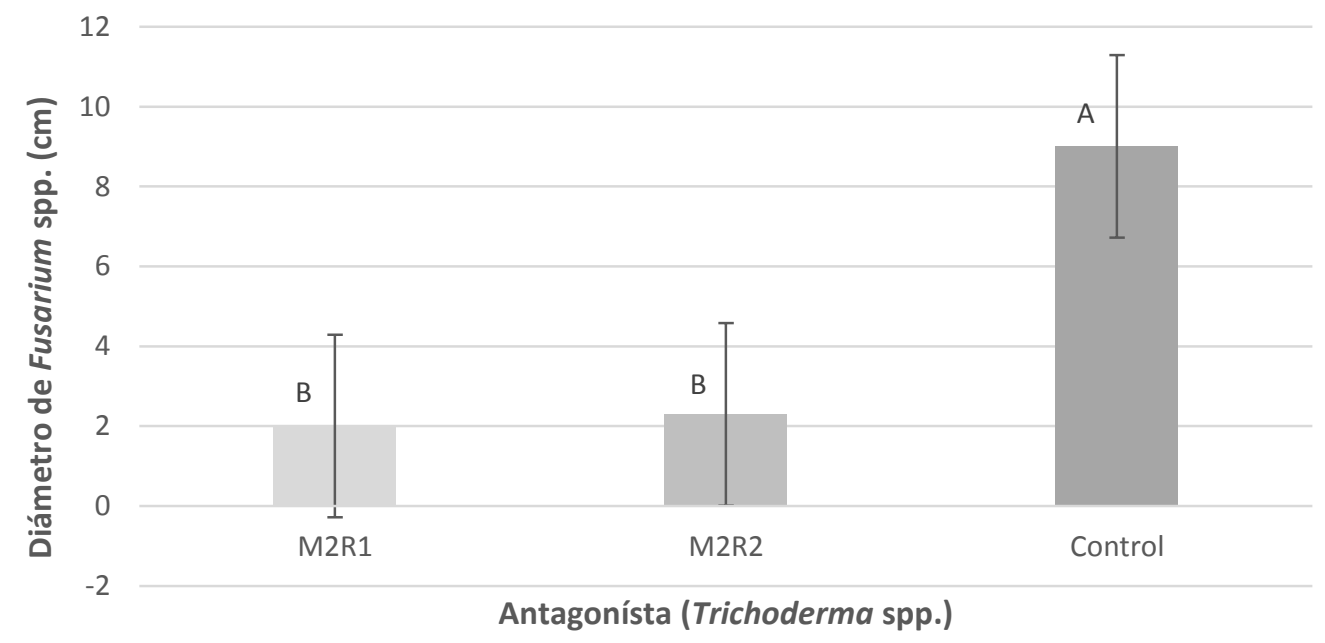

Figura 4. Efecto de cepas de Trichoderma en el diámetro de colonia de Fusarium spp. en ensayo de antagonismo por cultivos duales, después de diez días de incubación. 


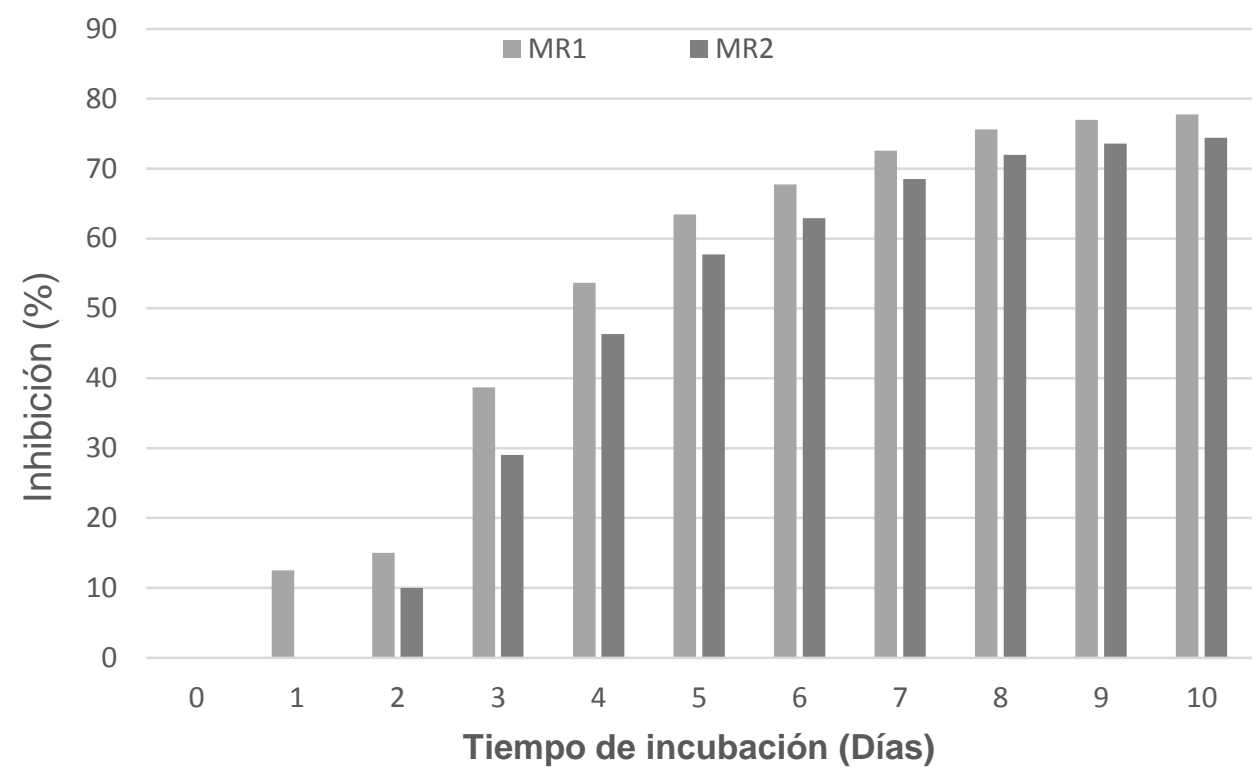

Figura 5. Efecto de cepas de Trichoderma sp. en la inhibición del diámetro de colonia de Fusarium spp. en ensayo de antagonismo por cultivos duales, durante diez días de incubación.

mayor afectividad antagónica (Figura 2) con respecto al resto de las cepas.

La eficacia del antagonismo de las cepas de Bacillus spp. frente a Fusarium spp. se evidencia mediante la inhibición del crecimiento obteniendo un $92.2 \%$ para la cepa TBa4.

Comparando ambos métodos de antagonismo empleados en el estudio, contacto directo y cultivos duales (Figura 3), las cepas de Bacillus spp. TBa 4, TBa 6, TBa 11 y TBa 18, mantuvieron el mayor efecto antagónico, evidenciándose su capacidad para producir metabolitos fungitóxicos y su rapidez de crecimiento para competir por espacio y nutrientes, debido al alto nivel de inhibición y crecimiento de Fusarium sp. en condiciones in vitro. Las cepas TBa 9 y $\mathrm{TBa} 10$ tuvieron una buena capacidad antagónica en una de las pruebas, no manteniendo la eficacia en la otra prueba.

Por otro lado, también se demostró la eficacia de Trichoderma spp. como antagonista de Fusarium spp. (Figura 4). Las dos cepas de Trichoderma M2R1 y M2R2 ensayadas, inhibieron el crecimiento de la colonia del patógeno a un diámetro de 2.0 y $2.3 \mathrm{~cm}$, respectivamente, equivalente a niveles de inhibición de $77.7 \%$ para M2R1 y $74.4 \%$ para M2R2 (Figura 5), con diferencias significativas $(\mathrm{p}<0.05)$ entre las cepas de Trichoderma y el tratamiento control.

Respecto a la actividad inhibitoria de especies de Trichoderma, en investigaciones como las de Bonilla (1990), empleando cepas de T. harzianun, T. viride, T. koningii, $T$. pseudokoningii sobre $F$. subglutinans alcanzaron rangos de inhibición desde 10 a $85 \%$, en donde $T$. harzianun, $T$. koningii y $T$. pseudokoningii particularmente alcanzan de 48 a $85 \%$, y $T$. viride entre 10 y $48 \%$, además de especificar que aislamientos de $T$. harzianun alcanzaron valores hasta de $84 \%$. Sin embargo, en las investigaciones de Hernández et al. (2006) reportan la inhibición para $F$. subglutinans, donde los mayores niveles de inhibición fueron por $T$. atroviride y $T$. harzianum con $48 \%$ para ambos antagonistas.

La capacidad antagonista de las especies de Trichodrema está reconocida ampliamente, siendo buenos competidores por el sustrato y con una actividad metabólica particular que los capacita como eficacia hiperparásitos de las estructuras fúngicas de los hongos (Ghisalverti \& Savisithaparam, 1991; Huang et al., 1996). En esta investigación, se verificó una mayor eficacia antagónica frente a Fusarium spp., de las cepas de Bacillus spp. sobre las de Trichoderma spp.

\section{Conclusiones}

El agente patógeno causante de la enfermedad del marchitamiento vascular progresivo (seca seca) en plantas de tara (Caesalpinia spinosa) es Fusarium spp. Cepas nativas de Bacillus spp. y Trichoderma sp. demostraron en condiciones in vitro capacidad antagónica frente a Fusarium spp. siendo las cepas de Bacillus spp. los que presentan mayor efecto de inhibitorio en el crecimiento micelial del patógeno.

\section{Agradecimientos}

Los autores agradecen el financiamiento para la ejecución de la investigación a la Universidad Nacional de San Cristóbal de Huamanga. 


\section{Literatura citada}

Acosta T., Avellaneda A., Cuervo J. \& Sánchez L. 2007. Evaluación de microbiota de tomillo (Thymus vulgaris) como aporte al manejo agroecológico de aromáticas en invernaderos. Perspectivas del agronegocio de hierbas aromáticas culinarias y medicinales. Universidad Nacional de Colombia.

Astorga K., Meneses K., Zúñiga C., Brenes J. \& Rivera W. 2013. Evaluación del antagonismo de Trichoderma sp. y Bacillus subtilis contra tres patógenos del ajo. Tecnología en Marcha, 27(2): 82-91.

Benítez T., Rincón A., Limón M. \& Codón A. 2004. Biocontrol mechanism of Trichoderma strains. International Microbiology. 7: 249-260.

Bonilla M. 1990. Utilización de especies de Trichoderma no controles biológico de Fusarium moniliforme Sheld. var. Subglutinans Wr. \& Rg. En: Abacaxi E. Ananas comusus (L.) Merril. Tesis de Maestría. Facultad de Agronomía, Universidad Federal da Bahía. Brasil.

Calvo P. \& Zuñiga D. 2010. Caracterización fisiológica de cepas de Bacillus sp. aisladas de la rizósfera de papa (Solanum tuberosum). Ecol. apl., 9(1): 31-39.

Carrillo L. 2003. Los hongos de los alimentos y forrajes. Universidad Nacional de Salta, Argentina.

Coca M. 2009. Enfermedades de la tara (Caesalpinia spinosa). Universidad Mayor de San Simón (UMSS). Departamento de Fitotecnia y Producción Vegetal. Laboratorio de Fitopatología. Serie de Publicaciones Fitopatológicas, 3(2): 1-5. Cochabamba, Bolivia.

Constanza L., Sánchez L., Cuervo J., Bautista D., González L. \& Guevara M. 2011. Evaluación del efecto biocontrolador de Bacillus sp., frente a Fusarium sp., bajo condiciones de invernadero en Rosmarinus officinalis L. Universidad Colegio Mayor de Cundinamarca. Colombia.

Corrales L., Sánchez L., Cuervo J., Joya A. \& Márquez K. 2012. Efecto biocontrolador de Bacillus sp. frente a Fusarium sp. bajo condiciones de invernadero en plantas de tomillo (Thymus vulgaris L.). NOVA, 10(17): 64-82.

De La Cruz P. 2004. Aprovechamiento integral y racional de la tara Caesalpinia spinosa - Caesalpinia tinctoria. Revista del Instituto de Investigación FIGMMG, 7(14): 64-73.
Fox F. 1993. Principles of diagnostic techniques in plant pathology. Wallingford: CAB International.

French E. \& Herbert T. 1980. Métodos de Investigación Fitopatológica. Libros y Materiales Educativos N 43. San José, Costa Rica. IICA.

Ghisalverti E. \& Sivasithamparam K. 1991. Antifungal Antibiotics Produced by Trichoderma sp. Soil Biol. Biochem., 23: 1010-1020.

Hernández A., Sierra A. \& Carr A. 2006. Evaluación in vitro del antagonismo de especies de Trichoderma sobre hongos fitopatógenos que afectan las vitroplantas de piña (Ananas comosus (1.) merr.) Fitosanidad, 10 (2): 105-108.

Huang Q., Tezuka Y., Kikuchi T., Nishi A., Tubaki K. \& Tanaka K. 1996. Studies on Metabolites of Mycopasarsitic fungi, Metabolites of Trichoderma Koningii. Chemical and Pharmaceutical Bulletin, 44(3): 590-593.

Injante P. \& Joyo G. 2010. Guía Técnica Manejo integrado de maíz amarillo duro. Universidad Nacional Agraria La Molina. Lima.

Layton C., Maldonado E., Monroy L., Constanza L. \& Consuelo L. 2011. Bacillus sp.; Perspectiva de su efecto biocontrolador mediante antibiosis en cultivos afectados por fitopatógenos. Universidad Colegio Mayor de Cundinamarca. Colombia.

Mitidieri L. 1988. Control biológico de hongos de suelo con Trichoderma in vitro. IDIA, 44: 45-49.

Monzón J. 2000. Infecciones causada por el género Fusarium sp. Tercera Edición. Centro de Investigaciones Microbiológicas. España.

Ogata K. \& Zúñiga D. 2008. Estudio de la microflora de la rizósfera de Caesalpinia spinosa en la provincia de Huánuco. Zonas Áridas, 12(1): 191-208.

Pitt J. \& Hocking A. 1997. Fungi and Food Spoilage. $2^{\circ}$ ed. Blackie Academic \& Professional, London, New York.

Valencia-Botín A. 2002. Etiología de la enfermedad "ojo de pescado" en pitahaya (Hylocereus undatus $\mathrm{H}$ ). Tesis de Maestría en Ciencias. Colegio de Postgraduados. Montecillo, México.

\footnotetext{
${ }^{1}$ Laboratorio de Biotecnología - Facultad de Ciencias Biológicas, Universidad Nacional San Cristóbal de Huamanga, Ayacucho - Perú.

${ }^{2}$ Laboratorio de Biotecnología - Facultad de Ciencias Biológicas, Universidad Nacional San Cristóbal de Huamanga, Ayacucho - Perú. Correo electrónico: paulagga30@hotmail.com.
} 